\title{
Juan Manuel de San Vicente, autor de comedias de santos en la Nueva España
}

Juan Manuel de San Vicente, author of saints’ comedies in New Spain

Felipe Reyes-Palacios*

* Universidad Nacional Autónoma de México, México Correo-e: freyes@unam.mx

Recibido: 1 de abril de 2019

Aprobado: 15 de julio de 2019
Resumen: Se estudian dos comedias de santos de Juan Manuel de San Vicente, rescatadas en forma parcial y editadas en 1990 por el latinista Germán Viveros, quien sostiene que sus características corresponden al Neoclasicismo. Se identifican una novela de Tirso de Molina y un poema épico de Cristóbal de Virués como las fuentes de que provienen una y otra. Mediante el método comparativo se demuestra que ambas se apartan del dogma de las 'unidades' de tiempo y lugar, aspecto característico del Neoclasicismo, y que el autor entretejió con la historia central otros episodios típicos de la comedia de enredo y del drama de honor, siguiendo la tradición de la comedia de santos española, de carácter híbrido y espectacular. Se concluye ubicando a este tipo de comedia, junto con otros géneros populares semejantes, como prerromántica.

Palabras clave: análisis literario; teatro; comedia; dramaturgo; producción teatral

Abstract: Two comedies of saints by Juan Manuel de san Vicente are studied; these were rescued partially and published in 1990 by Latinist Germán Viveros, who states that their characteristics correspond to the Neoclassicism. A novel by Tirso de Molina and an epic poem by Cristóbal de Virués are identified as the sources for one and the other. By means of the comparative method, it is demonstrated that both drift apart from the dogma of 'units' of time and place, a characteristic aspect of Neoclassicism and which the author interweaved with the main story other typical episodes of the comedy of intrigue and drama of honor, following the tradition of the Spanish comedy of saints, hybrid and spectacular in nature. The conclusion locates this sort of comedy, together with other similar popular genres, as pre-romantic.

Keywords: literary analysis; theatre; comedy; playwrights; theatrical production 
$\mathrm{T}$ an popular como era en la Península, la llamada comedia de santos no podía faltar en la Nueva España a finales del siglo XVIII, aun cuando hubiese sido prohibida la representación de este género y de los autos sacramentales en todo territorio español por la real cédula del 9 de junio de 1765. Es el caso de dos comedias rescatadas hace poco tiempo en forma parcial, escritas por Juan Manuel de San Vicente, quien se desempeñaba como administrador del Coliseo de la Ciudad de México hacia 1777. De También en la afrenta hay dicha fue recuperada tan sólo la jornada segunda, y por lo que toca a Lo mucho y poco que pueden los infernales ardides, únicamente la jornada primera. Incompletas como están, dejan traslucir, sin embargo, la estirpe a la que pertenecen; por lo demás, su fábula o anécdota completa se puede reconstruir en su línea principal valiéndonos de las probables fuentes de las que provienen una y otra, las cuales he identificado. Por su parte, el acucioso investigador Germán Viveros, su descubridor y editor, se ha empeñado en sostener, en el prólogo al libro en que las dio a conocer, que su impronta formal corresponde al Clasicismo $^{1}$ (1990: 1xxxiv-c), cuyos seguidores eran opuestos a la comedia de santos.

Viveros también reunió la escasa información que es dable encontrar acerca de Juan Manuel de San Vicente. Llegado éste a la Nueva España, probablemente en 1757 , antes había estado sujeto a las superiores órdenes del virrey Carlos Francisco de Croix en Galicia, "aquel gran reino [...] donde por suerte mía me crié” (San Vicente, en Germán Viveros, 1990: 1xxix), afirmaba en el prólogo-dedicatoria de una obra descriptiva suya acerca de lo principal de la Ciudad de México. Fue autor también de una comedia intitulada La sultana, la cual resultó “'tan mala', que el virrey Bucareli, quien asistía como espectador, prefirió salir del Coliseo", según glosa Viveros (1990: xxxii). Por último, quizá refundió también una

1 Toda la información acerca de San Vicente se encuentra en Viveros (1990). que otra comedia de algún autor español, rescribiéndola o adaptándola, labor nada rara en un administrador o asentista del Coliseo, preocupado por su repertorio. En resumen, San Vicente era un hombre de teatro, no un letrado ajeno a la escena, aunque hubiese tenido sus fracasos.

En su libro, Teatro dieciochesco de Nueva España, Viveros incluye también un "Discurso sobre los dramas" (1786), escrito por Silvestre Díaz de la Vega (éste sí un letrado de convicciones clasicistas), y un Reglamento para el Coliseo, del mismo año, solicitados ambos por el virrey conde de Gálvez, "para que la diversión pública del teatro de esta capital se hiciese con la decencia, decoro y arreglo debido a las buenas costumbres (por lo que respecta así a las piezas dramáticas que se ejecutasen, como a sus espectadores)" (1990: 213). También se recoge en el volumen de Teatro dieciochesco una "Noticia al público sobre la reforma general del Coliseo, hecha por D. Juan Manuel de San Vicente...", que él había dado a conocer, Viveros supone que tal vez un año antes, como preparándole el terreno al Reglamento ya en forma, el primero en su índole para el Coliseo. Sólo que, entre las reformas de que San Vicente daba cuenta, principalmente de índole administrativa y logística, no se incluía la prohibición de las comedias de santos, y en el Reglamento sí era expresa y enfática, como más adelante veremos. Ante la coyuntura en que Juan Manuel de San Vicente se encontraba, es de suponerse que en su labor de comediógrafo tendría que plegarse a los criterios oficiales de filiación clasicista.

La primera de sus obras que hemos mencionado, También en la afrenta hay dicha, es muy explícita acerca del género al que pertenece, pues en su segunda línea, después de ese título, se asienta: "San Pedro Armengol". A dicho santo, Tirso de Molina dedicó su novela El bandolero, incluida en su colección intitulada Deleitar aprovechando, la cual fue terminada en 1632 y se publicó tres años más tarde en Madrid. A esta edición se añadirían tres más hasta el siglo 
XVIII, todas las cuales pudo conocer Juan Manuel de San Vicente. Pero no sólo realizó Tirso esta versión novelada de la vida del santo, sino que también, como monje y cronista de su orden, el padre maestro fray Gabriel Téllez escribió una Historia general de la Orden de Nuestra Señora de las Mercedes, acabada varios años después, en 1639. La relación de la vida del santo abarca, ahí, una docena de folios. El asunto, pues, era digno de ser recordado en una crónica histórica, pero ofrecía mucho atractivo para ser novelado y dramatizado.

La fábula o historia de la vida completa de san Pedro Armengol abarca mucho más tiempo del que se podría incluir en la trama de una obra teatral, a menos que se ejecutara en la práctica aquella patraña de los comediógrafos españoles que consistía en presentar a un niño en mantillas en la jornada primera para concluir en la tercera cuando éste ya era hombre barbado. En el caso del 'divino Armengol', como le llamaba Tirso, su nacimiento sí está entrelazado con la santidad alcanzada por el hombre en el martirio, porque a ambos acontecimientos los une su carácter milagroso. Al nacer, Pedro Armengol es recibido por dos augurios; uno de ellos, formulado por un huésped de su casa que era "célebre en los juicios astrológicos” (Molina, 1979: 62), le es dejado por escrito a su padre, quien lo había solicitado; el otro lo profiere de manera espontánea un "varón santo y religioso" (Molina, 1979: 63), mercedario para más señas, quien también se contaba entre las visitas que estaban de paso. El anuncio del astrólogo sentencia que "sus fuerzas han de ser bizarras, pero su empleo tan desbaratado que, caudillo de salteadores, atajará sus travesuras un dogal infame que de un árbol le suspenda" (Molina, 1979: 65). Poco antes, y sin que el astrólogo estuviese presente, el varón religioso le dice a su padre, felicitándolo porque su primogénito hubiese sido escogido: "Estimad, sobrino generoso, las primicias de vuestro estado [de padre], que las destina el cielo para suyas
[...]. A este niño un patíbulo ha de hacerle santo" (Molina, 1979: 63).

Su padre, Alberto Armengol, quien a la sazón —en la segunda mitad del siglo XIII — era señor de la guardia de Montblanch, en el principado de Cataluña, naturalmente se alarma por aquello del dogal infame y el patíbulo, pues éstos comprometerían en el futuro el rancio abolengo del que provenía. Para no matarlo o abandonarlo en el bosque lo intercambia a escondidas por otro bebé que ese día había nacido muerto, hijo de un vaquero de su propio ganado. Crece así el hijo del noble con el nombre de Pedro Guillén, bajo el cobijo de una familia rústica, pero protegido especialmente por el señor de Montblanch, quien pensaba revelarle su verdadero origen en caso de que los augurios no se cumplieran.

Dos años después le nace una niña al matrimonio, que se había quedado sin descendencia, "una hija tan perfecta que desmintió su hermosura los descréditos de su sexo" (Molina, 1979: 74), y la llaman Saurina. Ella y Pedro crecen como amigos, ya que se ven con frecuencia y no saben que son hermanos, siendo amados ambos por su padre. Pedro Guillén estudia gramática y artes en Lérida, con lo que a su apostura natural, de noble, añadirá ahora un "sabroso estilo" (Molina, 1979: 133) con el que sabrá discurrir cuando sea necesario. Las prendas de Pedro están a la vista de Saurina,

\footnotetext{
y como la sangre que a Saurina animaba era la misma que en nuestro vaquero desmentía rustiquezas, hirvió sin fuego [la sangre] en las entrañas de la hermosa niña, de modo que, sin saber distinguir afectos, obligándola el alma a quererle como hermano, se le deslizó la voluntad a adorarle como amante (Molina, 1979: 81).
}

Novela de monarquismo ferviente, además de sus fines piadosos, en cada trance por el que transitará Pedro a partir de su juventud desmentirá 
'rustiquezas', como lo afirma otra mujer que se enamora de él: "No me persuadirán afirmaciones de Saurina a que esta vez, inadvertida, la naturaleza solamente cargue de tantas perfecciones a un sujeto, y la de más estima, que es la nobleza, se la niegue" (Molina, 1979: 182).

Y por lo que toca al amor que se profesan los dos hermanos, también a partir de entonces estará presente en todo momento la posibilidad del incesto, esto es, del pecado, ingrediente fundamental en las comedias de santos (Profeti, 2008: 243).

Múltiples complicaciones se atraviesan en su bucólica vida cuando acuden, ellos y un grupo de labradores, a la ciudad de Barcelona a divertirse en la feria del vidrio. Como consecuencia de un incidente propio de esas celebraciones multitudinarias, los dos conocen por casualidad a otros personajes que se enamorarán de una y otro: el privado del rey, don Berenguel Lanzol, y su hermana Laurisana. Terciará luego, pretendiendo a Saurina, el conde Manfredo, otro privado que compite con Lanzol, pero que de entrada se adivina perdedor a causa de las maquinaciones que va urdiendo.

Por cierto, entre el grupo de labradores que acude a la diversión aparece uno llamado Pinardo, con una participación menor (Molina, 1979: 142, 144, 146). Su nombre también será utilizado en la comedia de San Vicente (jornada segunda, escena primera), sólo que en el papel del padre falso de Pedro Guillén, quien se convierte en el gracioso de la comedia por el tono grotesco que emplea, deduciendo equivocadamente que había sido el cornudo de Alberto. Ésta es la única modificación que hace San Vicente a lo escrito por Tirso.

Estando pues, próximos a casarse, los Lanzoles con Saurina y el conde Manfredo, por deseo del rey, pero sin que las mujeres quieran hacerlo, ellas deciden huir con su amado Pedro, una a plena conciencia (Laurisana) y la otra engañada por un criado desleal (Saurina). Ambas van disfrazadas de hombre y huyen en medio de las tinieblas de la noche. Para entonces el conde ha provocado una riña callejera, como consecuencia de lo cual las damas se intercambian sin que nadie se dé cuenta hasta el día siguiente, cuando Saurina va con Pedro, en barco, con destino a Francia, y Laurisana con el criado desleal rumbo a Sicilia, donde el conde tiene posesiones.

Hasta el capítulo XIV, de veinte que integran El bandolero, tuvo que resumir San Vicente en la jornada primera, esto es, hasta que Pedro era un joven casadero, con todas las complicaciones que Tirso urdió, pues no figuran en la versión de la crónica (Molina, 1979: 13-17). A partir de aquí comienza la jornada segunda, con una extensión de ocho escenas, las cuales sintetizo de manera muy breve, indicando el lugar donde ocurren, para el análisis espacial.

Primera. Palacio del rey en Cataluña. Éste inculpa a Alberto de proteger a Pedro, incluyendo el secuestro de Laurisana. Lo aprehenden. Alberto se lamenta de no haber matado a su hijo de recién nacido.

Segunda. Exterior de un castillo en Sicilia. Laurisana supone que Pedro está muerto y piensa entrar en un monasterio. Cuando van a ejecutar a Guillermo —el criado desleal—, el ejército francés ataca y éste se salva.

Tercera. Bosque, en la frontera entre Francia y Cataluña. Saurina se queja del "tormento y rigor de Pedro", quien entonces le confiesa el secreto de su identidad, ya revelado por Alberto para evitar el incesto. Encabeza a más de trescientos bandoleros, saqueando por venganza las propiedades de los Lanzoles. Guillermo llega huyendo y Pedro ordena apresarlo.

Cuarta. Palacio del rey en Cataluña. El rey ordena atacar a los bandoleros de Pedro y acude a la "torre tenebrosa" a ordenar la muerte de Alberto. El conde se dirige en secreto a casarse con Saurina.

Quinta. Cárcel. Enviado por Pedro, Guillermo le lleva a Alberto una carta de aquél, pero el rey intercepta la misiva. Es la revelación de las deslealtades de Guillermo. Alberto se ve obligado a 
narrarle al rey toda la historia de Pedro, desde su nacimiento. El rey le ordena a Alberto dar muerte a Pedro por encabezar una banda de franceses. Berenguel sabe que su hermana entró a un convento y que Saurina conserva su honor.

Sexta. Bosque. Afligido (y distraído) por la pérdida de Laurisana, Pedro es aprehendido por Alberto, quien se dispone a ahorcarlo. Como prueba máxima de misericordia, sólo puede entregarle a su hijo un crucifijo. Tiernas escenas de súplica y despedida, al tiempo que Pedro va subiendo por una escala al árbol más alto. En golpe de efecto, Berenguel llega a caballo a perdonarlo por orden del rey.

Séptima. Cárcel. Condenado a muerte, el conde soborna a Pinardo, quien ahora hace de guardia, para que lo acerque a Guillermo, también preso. Le da una puñalada y se da otra a sí mismo. Los dos mueren.

Octava. Templo. Dirigiéndose las dos familias a agradecerle al rey el perdón de Pedro, éste decide orar en el templo de la Merced, donde la Virgen contesta sus rezos de viva voz. Le inspira ingresar a su Orden para convertirse en redentor de cautivos. El rey apadrinará su toma de hábito y el matrimonio de Saurina. El demonio hace rabietas. En este final se cumple apenas la predicción del astrólogo relativa al 'dogal infame'.

En la sucesión de ámbitos escénicos o decorados de que acabamos de dar cuenta (palacio, castillo, bosque, cárcel y templo) se manifiesta una libertad formal que no es propia del Clasicismo, como tampoco lo es el manejo del tiempo, que abarca muchos años, aunque no sabemos cuántos. Con su indiferencia ante las llamadas 'unidades aristotélicas', Juan Manuel de San Vicente se hurtaba al gusto de la élite novohispana, incluido el virrey, para satisfacer el del público que pagaba. Éste demandaba espectacularidad y golpes de efecto, como la entrada de Berenguel con el perdón real de última hora, a caballo y a través del patio del Coliseo, según acota el autor. Ya lo apunta Maria Grazia Profeti para el teatro español del siglo XVII: "el espectador que paga aprecia mucho la comedia de santos por su escenografía aparatosa y el uso de tramoyas; el género tiene un gran éxito, análogo al de la comedia de magia” (2008: 238). Y más adelante añade:

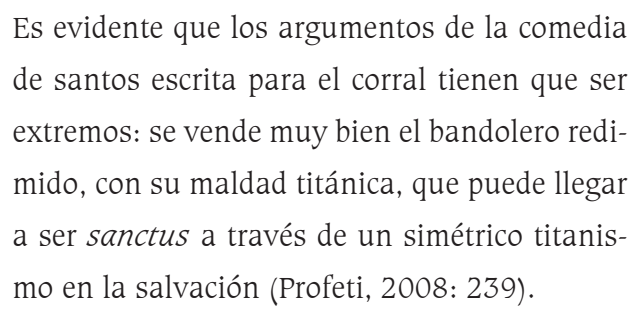
de santos escrita para el corral tienen que ser extremos: se vende muy bien el bandolero redimido, con su maldad titánica, que puede llegar a ser sanctus a través de un simétrico titanismo en la salvación (Profeti, 2008: 239).

Pero ésa es ya la conclusión de la historia, que ocurriría en la jornada tercera, de la cual carecemos. En El bandolero, de Tirso (capítulo XX), se nos narra que después de haber tomado el hábito mercedario Pedro viaja a tierra de infieles a rescatar cautivos; se queda allá como rehén y, a causa de que no llega el dinero dentro del plazo fijado, lo ahorcan en un árbol; ahí se queda colgado durante tres días. Cuando regresan los frailes mercedarios descubren que el padre Pedro Armengol no ha muerto. En Cataluña vivirá diez años más y, como perennes señales del hecho milagroso, le queda el cuello torcido y un palidísimo color en el rostro, con lo cual se cumplía el augurio del 'varón santo y religioso': el primogénito de Alberto sería santo.

En la otra comedia de San Vicente, De lo mucho y poco que pueden los infernales ardides, los extremos maniqueos de la comedia de santos son llevados un tanto más lejos, pues si en la anterior el pecado se reducía a las afrentas que Pedro le hacía al orden feudal y a la mera posibilidad del incesto, sin que él le diese jamás a su hermana ni un beso en la mejilla, ahora asistiremos a un suceso escabroso que sí ocurre, la violación de una doncella por parte de un anacoreta que hasta entonces había sido piadoso, el cual la degüella después y entierra su cuerpo en las soledades de Monserrate.

Se trata de la leyenda de Juan Garín o Guarino, ubicada en la segunda mitad del siglo VIII, que el asentista del Coliseo pudo haber adaptado 
del poema épico de Juan Cristóbal de Virués intitulado Historia del Monserrate (1945), publicado en Madrid en 1588, edición a la cual siguieron dos más hasta el siglo XVIII. En la versión de San Vicente el nombre del protagonista es, curiosamente, Guarín, como el regionalismo que designa en México al indígena otomí que no habla ni entiende el español.

Arrepentido de su crimen, Juan Garín viaja a Roma a pedir la absolución del papa, quien le impone la penitencia de que vuelva a su cueva de Cataluña a gatas. La parte milagrosa de la historia consistirá en que, después de que Garín le confiesa su crimen también al conde de Barcelona, Wifredo el Velloso, padre de la doncella asesinada, la buscan donde la enterró y ella aparece resucitada, con sólo una señal rosada en el cuello como señal de la herida que la había degollado.

La comedia de santos, en resumen, concentraba aspectos ambiguos o contradictorios en busca de la aceptación del público, como bien lo veía en España el padre Gaspar Díaz a mediados del siglo XVIII:

\begin{abstract}
Hay también comedias de santos; pero no totalmente inocentes, porque si son de pecadores convertidos $[\ldots]$ primero se pintan sus caídas y vicios con los vivos colores de la representación [...]; y si son de otros santos, siempre ó casi siempre se introduce algo profano en los papeles intrusos en la misma historia, ó á lo menos, se profaniza la santidad con los dichos del bufón y la graciosa. Y si la comedia nada de esto contuviera, se tuviera por insulsa (Gaspar Díaz, en Martínez Berbel, 2008: 39).
\end{abstract}

No era el gracioso el único elemento híbrido en estas comedias. En la que nos ocupa es muy notoria la intervención del adaptador, quien introduce una serie de complicaciones que les ocurren a dos parejas de nobles, quienes están a punto de casarse (entre ellos, la doncella que va a ser

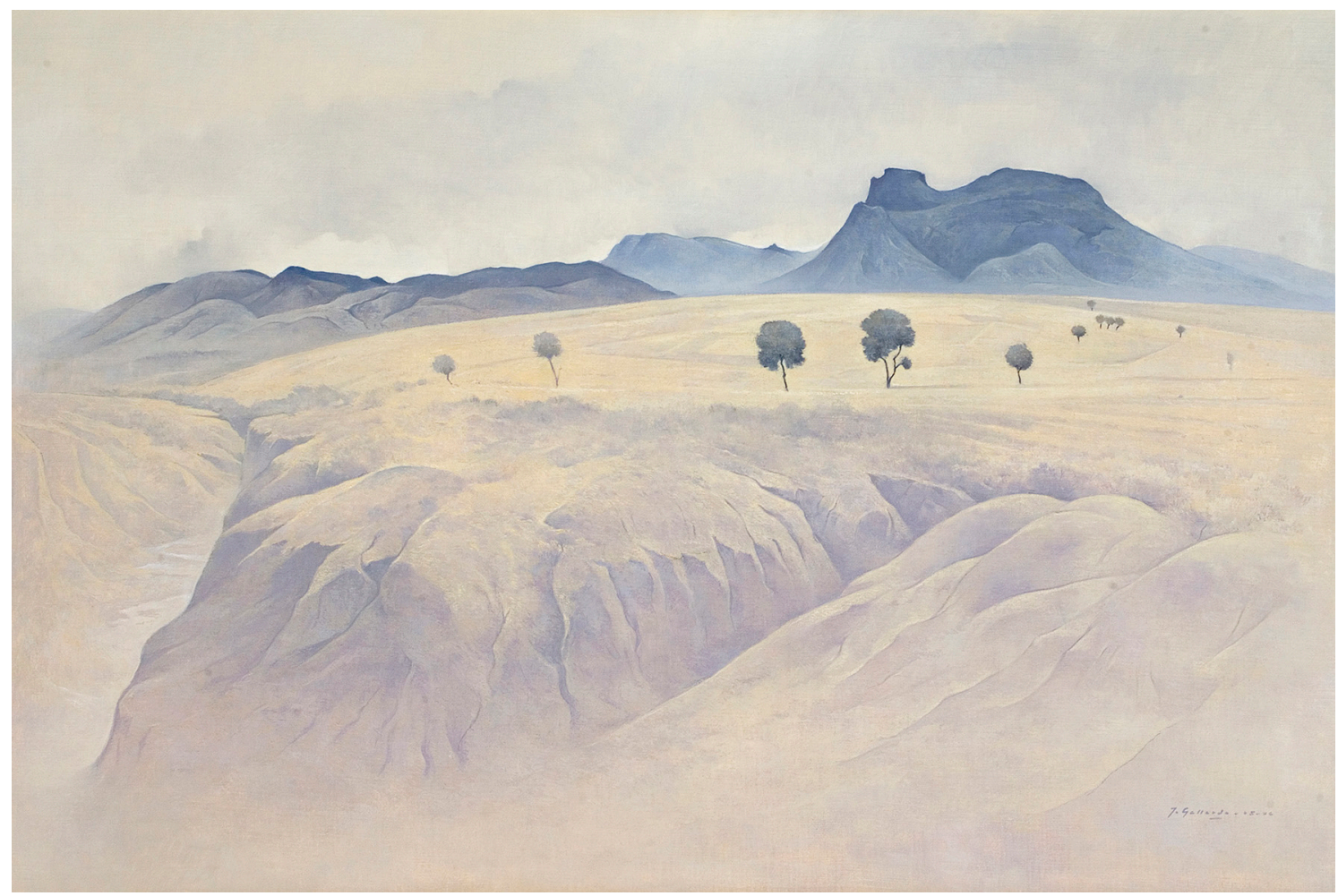

Paisaje grande de la Bufa (2006). Óleo sobre tela y madera: Jesús Gallardo.

Prohibida su reproducción en obras derivadas. 
degollada), y que conforman un auténtico drama de honor entre 'papeles intrusos', ajenos a la leyenda del anacoreta.

Por lo demás, la trama se ciñe a la versión del capitán Virués, sobre todo en los episodios de los ataques de dos demonios, uno que se posesiona de la doncella y otro que se le presenta a Garín disfrazado de ermitaño para mal aconsejarle y luego regocijarse con su crimen.

Huelga decir que aquí la libertad formal es idéntica a la que recurre San Vicente en su otra comedia. Por esa razón, historiadores del Romanticismo español, como E. Allison Peers, consideran a este género popular de índole espectacular - junto a otros similares, entre los que destaca la comedia de magia, la heroica y la sentimental-, francamente prerrománticos.

Como se deduce, la coyuntura ante la que se encontró Juan Manuel de San Vicente fue imposible de superar. Por una parte, como comediógrafo y asentista se inclinaba por las comedias de santos para satisfacer su gusto personal y sus intereses pecuniarios; por otra, el virrey conde de Gálvez intervino de repente en la administración del Coliseo, cancelando su contrato como asentista y estimulando la formación de una Sociedad de Accionistas para el mismo a causa de "los excesos y abusos que se han tocado" (Viveros, 1990: 213), como era el no respetar la real cédula de 1765. En otros términos: mientras Juan Manuel de San Vicente fue asentista del Coliseo se representaron ahí comedias de santos, incluidas las que él mismo escribió, pero no tuvo más remedio que entregar la administración de ese establecimiento a la instancia que el virrey dispuso, tal como se asienta en el artículo 1 del nuevo reglamento:

Justamente prohibida por el Rey, en resolución de 9 de junio de 1765, la representación de materias sagradas y las comedias de santos que tienen íntima conexión con ellas, no se permitirán de aquí adelante, con ningún pretexto ni motivo, a cuyo fin se recogerán y archivarán las que entregue el actual asentista del teatro, al tiempo de su traspaso a la Sociedad de Accionistas, sin embargo de cualesquiera licencia o permisión con que hasta aquí se hayan representado tales piezas, que no deben subsistir contra la expresa determinación del soberano (Viveros, 1990: 214).

Tal disposición nos acerca, primero, a una certidumbre. La "Noticia al público sobre la reforma general del Coliseo", que lleva como data tan sólo la frase "11 de abril", debe de ser del mismo año que el Reglamento, esto es, 1786, y muy probablemente la escribió San Vicente como un intento para detener la tormenta que se le venía encima, por haber cometido "excesos y abusos" en la elección de su repertorio.

Y luego nos deja una interrogante que tendría que ser resuelta si fuese posible: ilas dos jornadas aisladas que hemos revisado se conservaron precisamente por tal disposición, ya que fueron recogidas y archivadas por el aparato virreinal? De haber sido así, ¿ por qué se extraviaron las cuatro jornadas faltantes? Nos queda la duda también de que San Vicente hubiese nacido en Galicia, a causa de su fervor por los temas catalanes. Quizá algún día despejemos ambas incógnitas.

\section{REFERENCIAS}

Martínez Berbel, Juan Antonio (2008), "La comedia de santos entre la heterodoxia y la licitud”, en Felipe B. Pedraza Jiménez y Almudena García González (coords.), La comedia de santos. Coloquio Internacional Almagro, 1, 2 y 3 de diciembre de 2006: Actas publicadas con la participación de la Casa de Velázquez, Almagro, Universidad de Castilla-La Mancha, pp. 39-52.

Molina, Tirso de (1979), El bandolero, Madrid, Castalia.

Profeti, Maria Grazia (2008), "La comedia de santos entre encargos, teatro comercial, texto literario", en Felipe B. Pedraza Jiménez y Almudena García González (coords.), La comedia de santos. Coloquio Internacional Almagro, 1, 2 y 3 de diciembre de 2006: Actas publicadas con la participación de la Casa de Velázquez, Almagro, Universidad de Castilla-La Mancha, pp. 233-254.

Virués, Cristóbal de (1945), "Historia del Monserrate", en Poemas épicos, t. I, Madrid, Atlas, pp 503-573. 


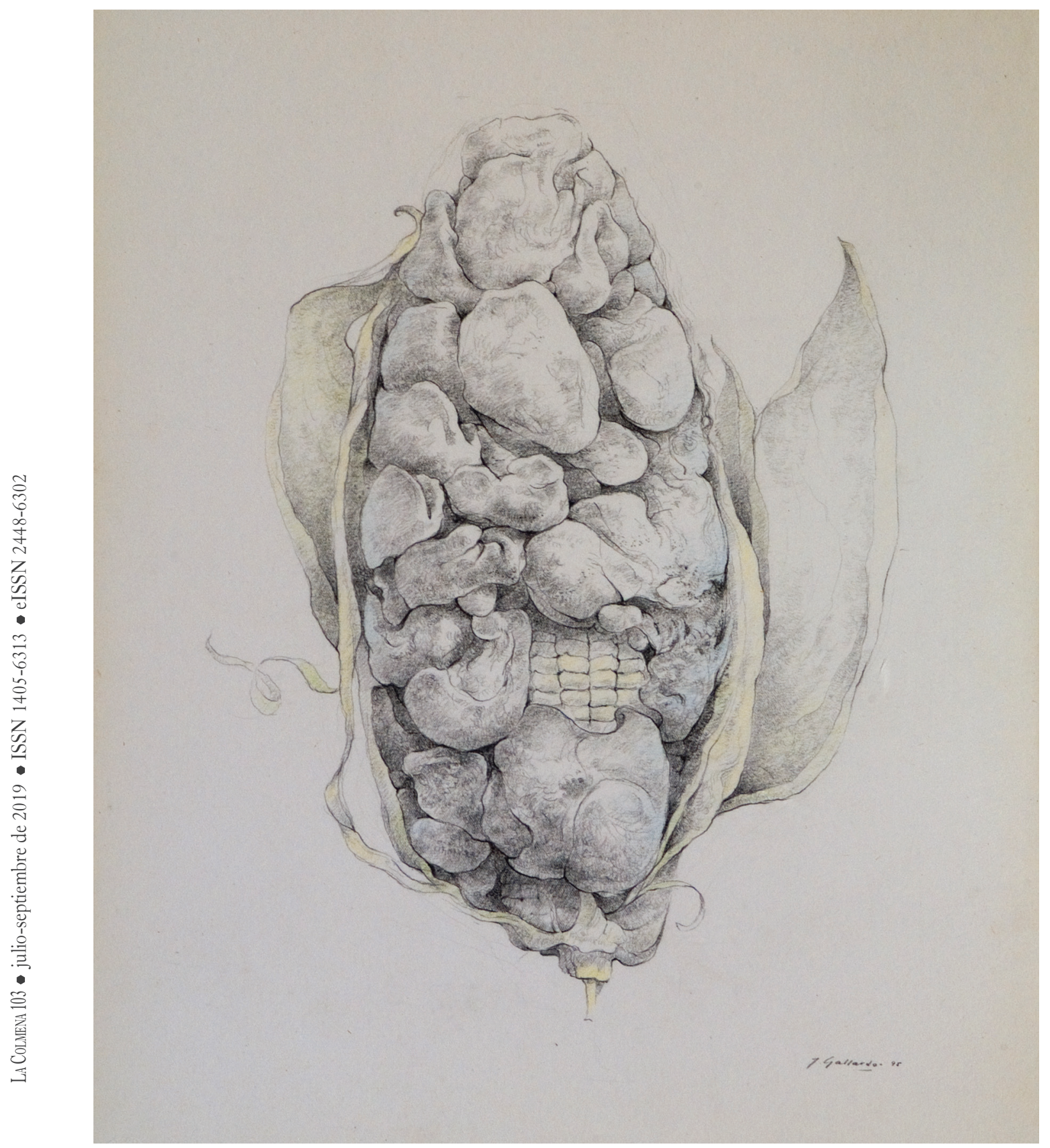

Gran huitlacoche (1995). Grafito sobre papel hecho a mano: Jesús Gallardo.

Prohibida su reproducción en obras derivadas.

Viveros, Germán (1990), Teatro dieciochesco de Nueva España, México, Universidad Nacional Autónoma de México.
Felipe Reyes Palacios. Doctor en Letras Mexicanas por la Universidad Nacional Autónoma de México (UNAM), México. Adscrito al Instituto de Investigaciones Filológicas de la misma institución. Sus publicaciones recientes incluyen el libro Manuel Eduardo de Gorostiza en su contexto dramatúrgico (UNAM, 2009) y dos recopilaciones de ensayos y artículos editados y prologados: Los frutos de Luisa Josefina Hernández (UNAM, 2011) y La mirada crítica de Luisa Josefina Hernández (UNAM, 2015). 